\title{
CÁC YẾU TỐ ẢNH HƯởNG ĐẾN Ý ĐỊNH MUA XE MÁY ĐIỆN VINFAST CỦA NGƯỜI DÂN TRỀN ĐỊA BÀN TP.HCM
}

\author{
TRÀN THU THẢO, TRÀN KHÁNH LINH \\ Khoa Quản trị kinh doanh, Truờng Đại học Công nghiệp Thành phố Hồ Chí Minh \\ tranthuthao@iuh.edu.vn
}

Tóm tắt: Mục đích của nghiên cứu này là xác định các yếu tố ảnh hưởng đến ý định mua xe máy điện Vinfast của người dân trên địa bàn TP.HCM. Nghiên cứu được thực hiện bằng phương pháp lấy mẫu phi xác suất với 153 người tham gia khảo sát đều đang học tập, làm việc trên địa bàn TP.HCM. Nghiên cứu đã sử dụng phần mềm SPSS để thực hiện: Thống kê mô tả, kiểm định Cronbach's Alpha, EFA, hồi quy tuyến tính và Anova để xử lý dữ liệu. Kết quả cho thấy 6 yếu tố: (1) Nhận thức về môi trường, (2) Thái độ, (3) Nhận thức kiểm soát hành vi, (4) Sự hấp dẫn của phương tiện khác, (5) Chuẩn chủ quan, (6) Chính sách khuyến mãi có tác động đến ý định mua xe máy điện Vinfast của người dân trên địa bàn TP.HCM. Trong đó biến Thái độ có tác động mạnh nhất. Từ kết quả nghiên cứu đó tác giả đưa ra một số hàm ý quản trị nhằm gia tăng ý định mua xe máy điện Vinfast của người dân trên địa bàn TP.HCM.

Từ khóa: Vinfast, xe máy điện Vinfast, phương tiện xanh

\section{FACTORS AFFECTING THE INTENTION TO BUY VINFAST ELECTRIC MOTORCYCLE OF PEOPLE IN HO CHI MINH CITY}

\begin{abstract}
The purpose of this research is to determine the factors that influence the customer's intention to buy a Vinfast electric motorbike in Ho Chi Minh city. The research is conducted by the non-probability sampling on 153 respondents. The research is analysed by SPSS software with the methods: Descriptive statistics, Cronbach Alpha coefficient testing, EFA, linear regression, Anova. The results show that there are 6 factors: (1) perceived environment, (2) attitude, (3) perceived behavioural control, (4) appeal of the vehicle, (5) subjective norm, (6) promotion policy that affect the purchase intention to Vinfast electric motorbike of people living in Ho Chi Minh city, in which the "Attitude" has the strongest influence. From the results, the author proposes a number of administrative implications in order to increase the intention to buy Vinfast electric motorbike of customers in Ho Chi Minh city.
\end{abstract}

Keywords: Vinfast, Vinfast electric motorbike, green vehicle

\section{GIỚI THIÊUU}

Thành phố Hồ Chí Minh là một trong những địa bàn có số lượng lớn người tham gia giao thông, đặc biệt là con số 8 triệu phương tiện các loại lưu thông mỗi ngày (Minh, 2020), khiến tình trạng ô nhiễm môi trường và ô nhiễm không khí ngày càng nặng nề theo lời nhận định của TS Mai Thanh Dung - Phó viện trưởng Viện Bảo vệ môi trường, Bộ TN\&MT (Trung, 2018). Một kết quả đo lường về vấn đề ô nhiễm môi trường của tổ chức công nghệ IQAir, Việt Nam xếp hạng thứ 21 về mức độ ô nhiễm không khí gây thiệt hại lên đến 14 tỷ USD mỗi năm (IQAir, 2020). Theo nguồn báo điện tử Thanh Niên, chính phủ và các cơ quan ban ngành đưa ra các chính sách ưu đãi hỗ trợ khuyến khích người tiêu dùng chuyển đổi từ phương tiện truyền thống sang các loại phương tiện như xe điện. Đó chính là một trong những động lực to lớn để khách hàng chọn xe điện thay vì xe máy xăng. Các nghiên cứu liên quan cũng đã nhận định rằng xe điện hoàn toàn tiết kiệm năng lượng và bảo vệ môi trường hơn so với xe máy chạy xăng (Ma \& cộng sự, 2017)

Theo số liệu thống kê từ Motorcycles Data, Vinfast đã có sự đóng góp vô cùng to lớn vào thị trường xe điện tại Việt Nam và để lại những hình ảnh tích cực trong tâm trí người tiêu dùng như trong quý I.2021 xe máy điện Vinfast đã bán ra 29.018 xe, tăng 21,6\% so với năm ngoái (Ngà, 2021). Tại thị trường Việt Nam, thương hiệu xe máy điện Vinfast hiện tại đang là một trong top 3 thương hiệu xe máy điện có thị phần lớn nhất (Ngà, 2021). Một nhận định của (Wang \& Hazen, 2016) đã cho rằng nếu người tiêu dùng có mức độ quen thuộc với một sản phẩm dịch vụ thì sau đó mức độ hiểu biết và nhận thức về sản phẩm của họ sẽ khác 
nhau từ đó cũng sẽ ảnh hưởng đến ý định mua hàng của họ. Chính vì thế mà ở nghiên cứu này tác giả muốn tìm hiểu những yếu tố nào khiến khách hàng lựa chọn xe máy điện Vinfast, mức độ được quan tâm của các nhân tố, những đề xuất quản trị nào sẽ sẽ phù hợp cho các nhà quản lý. Từ những lý do trên, tác giả thực hiện đề tài: "Nghiên cứu các yếu tố ảnh hưởng đến ý định mua xe máy điện Vinfast của người dân trên địa bàn Thành phố Hồ Chí Minh" làm đề tài nghiên cứu.

\section{CƠ SỞ LÝ THUYẾT VÀ MÔ HÌNH NGHIÊN CỨU}

\subsection{Co sở lý thuyết}

\subsubsection{Khái niệm xe máy điện Vinfast}

Theo định nghĩa của Bách khoa toàn thư Wiki về xe máy điện là phương tiện giao thông sử dụng động cơ chạy bằng năng lượng điện. Xe máy điện sẽ không dùng bàn đạp như các loại xe đạp điện thông thường. Điện để chạy động cơ xe thường được lưu trữ dưới cục pin sạc. Xe máy điện và các phương tiện sử dụng nhiên liệu xanh, thân thiện với môi trường đang được mọi người chú trọng như là một cách giải quyết tình trạng ô nhiễm môi trường.

Ở giai đoạn cuối năm 2018, với tiêu chí bền đẹp - thông minh - sinh thái, thương hiệu Việt - Vinfast phát triển nhà máy sản xuất có diện tích 335 hecta nằm tại khu vực Hải Phòng và tung mẫu xe máy điện đầu tiên tên VinFast Klara với 2 phiên bản: phiên bản cao cấp Lithium-ion và phiên bản Acid-chi đã đạt được con số vô cùng ấn tượng. Số lượng đặt hàng lên đến 50.000 xe máy điện hoàn toàn có thể đáp ứng các đặc thù của giao thông và khí hậu tại thị trường $\mathrm{VN}$ không thua kém gì các dòng xe máy truyền thống của các thương hiệu lớn khác. Ngoài ra Vinfast còn phát triển 600 trạm đổi pin và hệ thống xe đổi pin lưu động.

Tính đến thời điểm này, Vinfast sở hữu cho mình 3 dòng xe máy điện: Vinfast Klara, Vinfast Ludo, Vinfast Impes với mức giá giao động chỉ từ 12,9 triệu đồng. Xe máy điện Vinfast được mọi người đánh giá cao về chât lượng cao, sở hữu các tính năng hiện đại và thân thiện với môi trường tuy nhiên cũng có một số ý kiến cho rằng mức giá của các loại xe máy điện thương hiệu Vinfast quá cao so với mong đợi của khách hàng trên thực tế giá xe Klara có mức giá dao động dưới 30 triệu trong khi đó xe điện của Ân Độ giá khoảng 20 triệu chất lượng tương đương, sạc pin còn khá lâu, v.v.

\subsubsection{Mô hình Hành vi người tiêu dùng}

Theo (Kotler, 2007), các nhà quản trị cần nghiên cứu khách hàng một cách triệt để bằng cách đặt câu hỏi $5 \mathrm{~W}-1 \mathrm{H}$ như khách hàng đang cần sản phẩm gì, mua ở đâu, khi nào sẽ phải mua, tại sao phải mua, ai đang cần sản phẩm đó và cuối cùng là mua như thế nào.

\begin{tabular}{|l|l|}
\hline \multicolumn{2}{|c|}{ Các nhân tố kích thích } \\
\hline Marketing & \multicolumn{1}{|c|}{ Môi trường } \\
\hline - Sản phẩm & - Kinh tế \\
- Giá cả & - KH-KT \\
- Phân phối & - Chính trị \\
- Chiêu thị & - Văn hóa \\
& - Cạnh tranh \\
\hline
\end{tabular}

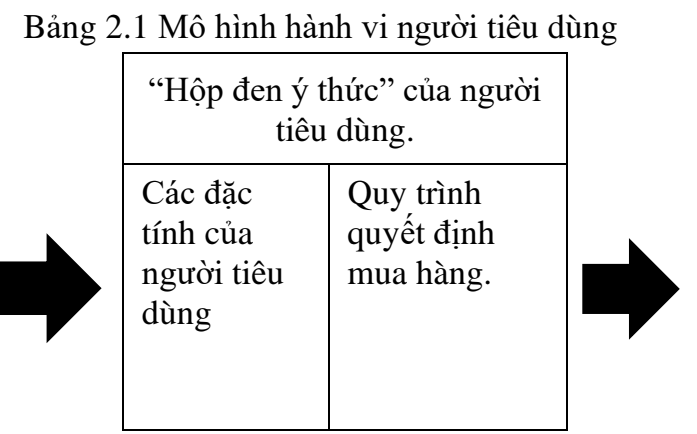

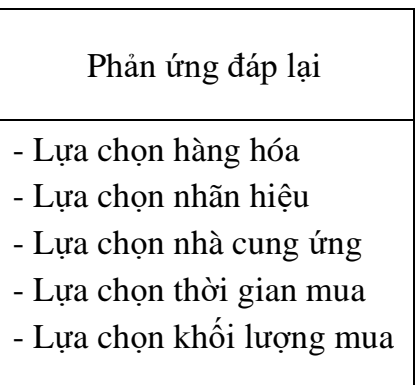

Nguồn: (Philip Kotler, 2007)

Đầu tiên là ô Các nhân tố kích thích bao gồm các yếu tố kích thích của Marketing (sản phẩm, giá cả, phân phối, chiêu thị) và các tác nhân của Môi trường (kinh tế, khoa học kĩ thuật, chính trị, văn hóa, cạnh tranh) dẫn đến "Hộp đen ý thức" của người tiêu dùng. Nhờ vào các yếu tố bên trong của "Hộp đen ý thức" mà từ đó xảy ra hàng loạt phản ứng đáp trả mà nhà quản trị có thể dễ dàng nhìn thấy được, đo lường được như: lựa chọn hàng hóa, lựa chọn nhãn hiệu, lựa chọn nhà cung ứng, lựa chọn thời gian mua và cuối cùng là lựa chọn khối lượng mua. Chính vì vậy, chúng ta cần phải thẩu hiểu những điều nằm bên trong hộp đen ý thức của người tiêu dùng.

Bên trong "hộp đen ý thức" ta cần phải xem xét các vấn đề như sau: thứ nhất, các đặc tính như (các yếu tố văn hóa, xã hội, cá nhân và tâm lý) ảnh hưởng đến người tiêu dùng như thế nào. Thứ hai, người tiêu dùng có lần lượt trải qua 5 giai đoạn mua hàng hay có sự thay đổi trình tự mua hàng, bỏ bớt giai đoạn hay không. 
Tóm lại, mô hình nghiên cứu hành vi người tiêu dùng sẽ giúp nhà quản trị hiểu được phản ứng của khách hàng đối với sản phẩm mà doanh nghiệp mình cung cấp như: lợi ích của sản phẩm, các chương trình chiêu thị hấp dẫn, lựa chọn kênh phân phối,... Nếu các doanh nghiệp nắm rõ được mô hình hành vi người tiêu dùng một cách cụ thể chi tiết nhất sẽ dễ dàng có được những chiến lược kinh doanh, tiếp thị có tính hiệu quả cao.

\subsubsection{Khái niệm Ý định mua}

Theo (Ajzen \& Fishbein, 1975) định nghĩa rằng hành vi ý định (Behavior Intention) là ý định thực hiện một hành vi cụ thể nào đó và bị ảnh hưởng bởi hai yếu tố: Thái độ (Attitude) của người tiêu dùng về hành vi đó, yếu tố thứ hai là Chuẩn chủ quan (Subjective Norm) có liên quan đến ý định hành vi. Ý định mua là đề cập đến một kế hoạch của người tiêu dùng có thể sẽ được thực hiện để mua sản phẩm, dịch vụ. Hành vi mua thường được thúc đẩy bởi yêu cầu bắt buộc, hoặc là nhu cầu được phát sinh ở một thời điểm nào đó (Lu \& cộng sự, 2014).

Một định nghĩa khác của (Ajzen, 2002) hành vi ý định là bị ảnh hưởng bởi ba loại niềm tin: Niềm tin về hành vi, Niềm tin chuẩn tắc, Niềm tin kiểm soát. Tác giả cho rằng thái độ, chuẩn chủ quan và khả năng kiểm soát nhận thức càng cao thì ý định thực hiện hành vi mua càng trở nên mạnh.

Tóm lại, ý định mua là một dự định của người tiêu dùng trước khi ra quyết định mua một sản phẩm hay sử dụng một dịch vụ nào đó trong tương lai. Để đi từ ý định mua sang quyết định mua không hề dễ dàng vì nó có thể sẽ bị ảnh hưởng bởi rất nhiều yếu tố tác động đến.

\subsubsection{Các mô hình lý thuyết liên quan}

\section{Thuyết hành động hợp lý (Theory of Reasoned Action - TRA)}

Mô hình TRA có tên gọi tiếng anh là Theory of Reasoned Action, là mô hình dự báo về ý định mua của (Ajzen \& Fishbein, 1975) bao gồm hai yếu tố chính trong mô hình đó là Thái độ đối với hành vi và Chuẩn chủ quan để tác động đến Ý định hành vi, dẫn đến hành vi cuối cùng.

Tuy nhiên (Ajzen \& Fishbein, 1975) nhận định vẫn hạn chế ở mô hình TRA, giả định rằng hành vi được quyết định dựa trên ý định thực hiện hành vi đó. Cho nên lý thuyết này chỉ áp dụng đối với hành vi đã có ý định từ trước.

Người tiêu dùng hình thành ý định mua thì họ sẽ tự do hành động nhưng nhiên trong thực tế, hành động sẽ bị ảnh hưởng rất nhiều từ môi trường bên ngoài, thuyết TRA cho phép dự đoán và giải thích xu hướng để thực hiện hành vi bằng thái độ hướng đến hành vi của người tiêu thay vì hướng đến một sản phẩm hay dịch vụ của doanh nghiệp (Mitra Karami, 2006).

\section{Thuyết hành vi dụ định (Theory of Planned Behavior - TPB)}

Theo (Ajzen, 1991), khái niệm này được kế thừa và phát triển từ khái niệm Lý thuyết hành vi hợp lý (TRA - Theory of Reasoned Action) của (Ajzen \& Fishbein, 1975). Mô hình TPB được tạo ra để khắc phục sự hạn chế của lý thuyết trước về việc cho rằng hành vi của con người bị kiểm soát bởi lý trí và còn được xem là mô hình tối ưu hơn so với mô hình TRA.

Nhận thức kiểm soát hành vi thể hiện qua việc dễ dàng hoặc khó khăn khi thực hiện một hành vi cụ thể hoặc việc thực hiện hành vi đó có bị hạn chế gì hay không (Ajzen, 1991).

\section{Thuyết chấp nhận công nghệ (TAM)}

Theo (Davis, 1986), mô hình chấp nhận công nghệ (TAM) được cho rằng nó được xuất phát từ lý thuyết hành động hợp lý (TRA), liên quan đến vấn đề dự đoán các khả năng chẩp nhận một công nghệ mới. Mô hình chấp nhận công nghệ được được các định bởi hai yếu tố đó là nhận thức tính hữu ích (Perceived Usefulness) và nhận thức dễ sử dụng (Perceived Ease Of Use).

Trong nghiên cứu của (Taylor \& Todd, 1995) bổ sung Chuẩn chủ quan và Nhận thức kiểm soát hành vi vào mô hình khi kết hợp giữa TAM và TPB. Xe máy điện là sản phẩm của phát triển công nghệ "xanh", do đó sử dụng mô hình chấp nhận công nghệ TAM vào việc giải thích ý định chấp nhận một công nghệ "xanh" là việc hoàn toàn hợp lý. 


\subsubsection{Các nghiên cứu liên quan}

Nghiên cúu về "Phát triển xe điện ở Bắc Kinh: Phân tích về hành vi ý định của người tiêu dùng" của tác giả (Huang \& Ge, 2019)

Tác giả chọn thành phố Bắc Kinh là phạm vi được khảo sát bởi vì đây nơi được quảng bá rộng rãi sản phẩm xe điện ở Trung Quốc. Dựa trên cơ sở lý thuyết TPB ba biến: Thái độ, Chuẩn chủ quan, Nhận thức kiểm soát hành vi để đi đến ý định mua hàng. Bài báo này chú trọng biến Thái độ tác động mạnh nhất đến việc mua xe máy điện của người tiêu dùng Bắc Kinh. Lý thuyết TPB được sử dụng làm cơ sở cho bài luận và thu được tổng số 502 cuộc khảo sát hợp lệ. Kết quả nghiên cứu cho rằng Thái độ, Nhận thức kiểm soát hành vi, Chuẩn chủ quan, Nhận thức sản phẩm, Các biện pháp chính sách khuyến khích tiền tệ ảnh hưởng tích cực đến ý định mua xe điện của người dân Bắc Kinh. Bên dưới là mô hình và các giả thuyết của hai tác giả.

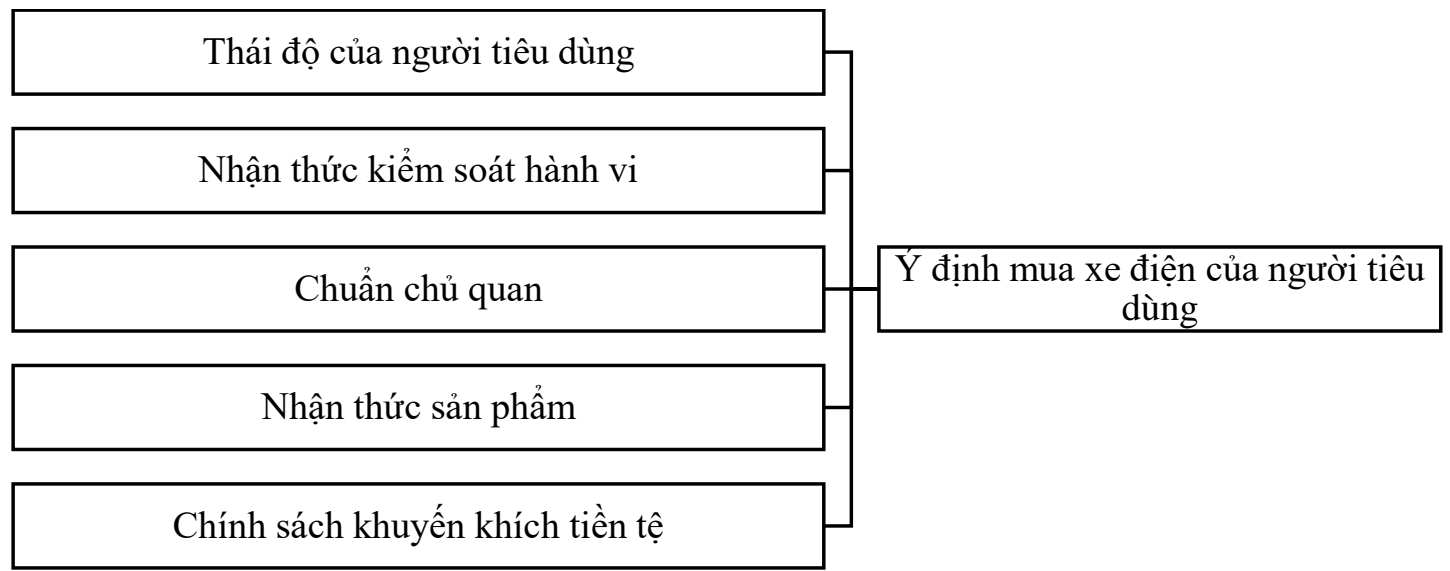

Hình 2.1 Phát triển xe điện ở Bắc Kinh: Phân tích hành vi người tiêu dùng

Nguồn: (Huang \& Ge, 2019)

Nhóm tác giả kết luận rằng thái độ của người tiêu dùng, nhận thức kiểm soát hành vi, chuẩn chủ quan, các chính sách khuyến khích tiền tệ, nhận thức sản phẩm có tác động tích cực đến ý định mua xe máy điện tại thành phố Bắc Kinh, còn các yếu tố còn lại thì được xem là không có tác động đáng kể đến ý định mua hàng. Thêm vào đó, kết quả nghiên cứu nhóm đưa ra kết quả có sự khác biệt lớn về biến nhân khẩu học trong ý định mua hàng của người tiêu dùng.

Nghiên cúu về "Phân tích các yếu tố ảnh hưởng đến ý định mua xe máy điện của người dân trên địa bàn quận Ninh Kiều - Cần Tho" của tác giả (Trang, 2018).

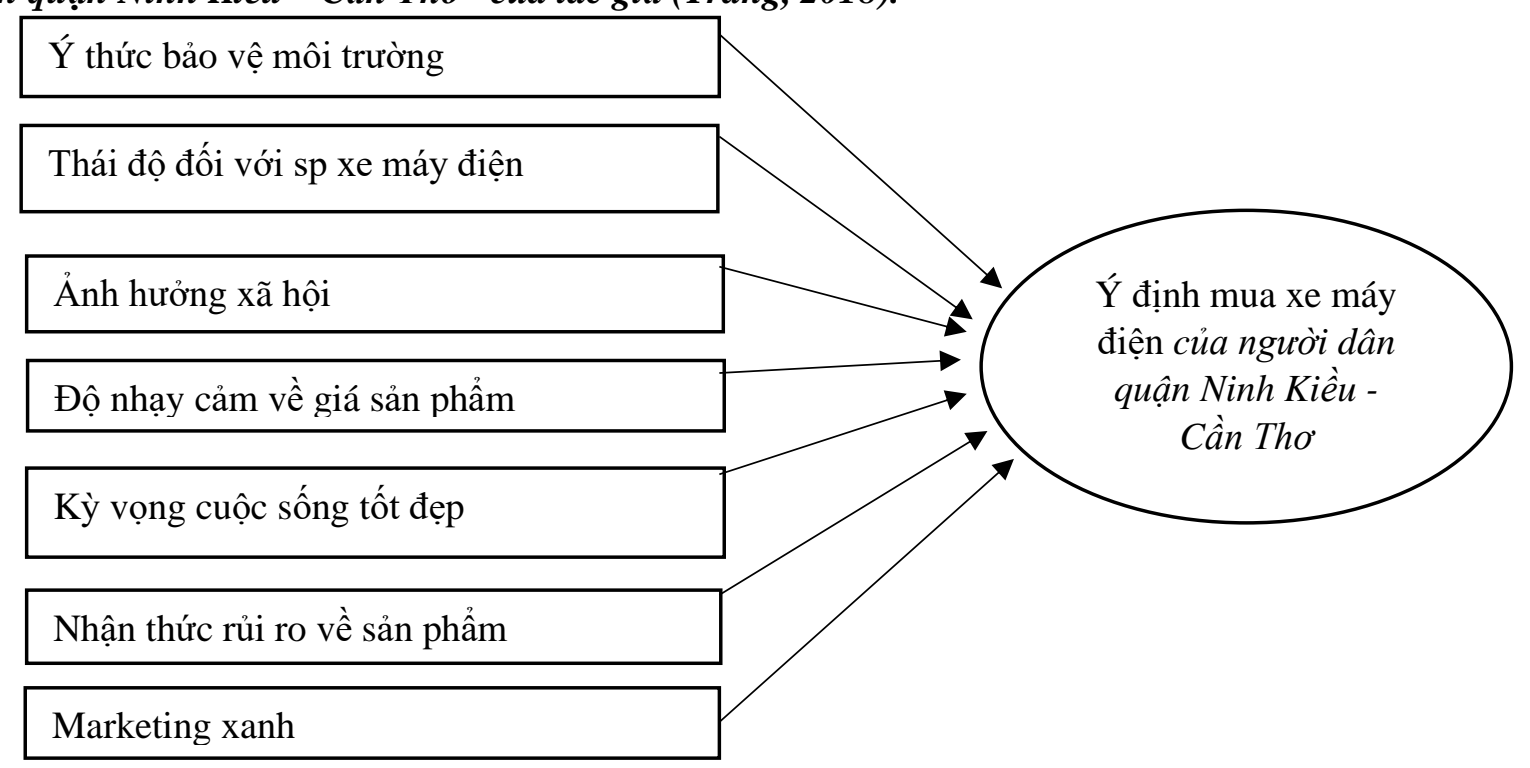

Hình 2.2 Mô hình Ý định mua xe máy điện của người dân quận Ninh Kiều - Cần Thơ

Nguồn: (Trang, 2018) 
Tác giả giới thiệu sản phẩm xanh trong đề tài của mình là xe máy điện, phạm vi nghiên cứu là tại địa bàn quận Ninh Kiều - Cần Thơ. Thu nhập được 170 bảng khảo sát của người dân có sự quan tâm về sản phẩm xe máy điện thân thiện môi trường, mô hình đề xuất 7 nhân tố chính tác động đến ý định mua xe máy điện của người dân quận Ninh Kiều - Cần Thơ đó là Ý thức bảo vệ môi trường, Thái độ, Ảnh hưởng xã hội, Độ nhạy cảm về giá, Sự kỳ vọng, Nhận thức rủi ro. Trong đó nhân tố Ý thức bảo vệ môi trường ảnh hưởng nhiều nhất đến ý định mua xe máy điện.

Sau khi phân tích số liệu, cả 7 nhân tố đều được giữ nguyên trong mô hình Ý định mua xe máy điện của người dân trên địa bàn quận Ninh Kiều - Thành phố Cần Thơ, tác giả này đã đề xuất một số hàm ý quản trị xoay quanh 7 nhân tố như doanh nghiệp cần nâng cao nhận thức bảo vệ môi trường, tăng sự trải nghiệm của khách hàng đối với sản phẩm, xây dựng các chiến lược marketing xanh. Tuy nhiên, bài nghiên cứu này vẫn có một vài hạn chế như chỉ tập trung phạm 23 vi khảo sát người dân khu vực Ninh Kiều - Thành phố Cần Thơ nên sự đóng góp chưa mang tính khái quát cao.

\subsection{Mô hình và Giả thuyết nghiên cứu}

\subsubsection{Nhận thức về môi trường}

Theo nghiên cứu của (Yi-Chang \& Gwo-Hshiung, 1999) đưa ra rằng Nhận thức về môi trường liên quan đến các nhận thức về ô nhiễm môi trường, kiến thức về môi trường và tiết kiệm năng lượng trên hành vi của người dùng. Các biến quan sát liên quan đến vấn đề nhận thức về môi trường từ bài nghiên cứu (Trang, 2018) và (Dung, 2012) là nhận thức về môi trường, trách nhiệm xã hội, nhận thức lợi ích từ hành động, thói quen sử dụng phương tiện truyền thống. Ngoài ra (Thogersen, 1999) còn chứng minh hành vi thân thiện với môi trường có xu hướng lây lan sang nhiều lĩnh vực khác như phân loại rác tái chế, sử dụng phương tiện di chuyển xanh thân thiện với môi trường, v.v. Do đó, biến Nhận thức về môi trường là một biến phù hợp để nghiên cứu đề tài Ý định mua xe máy điện Vinfast.

Giả thuyết H1: Nhận thức về môi trương tác động cùng chiều (+) đến ý định mua xe máy điện Vinfast của người dân trên địa bàn TP.HCM.

\subsubsection{Thái độ}

Thái độ tích cực hoặc tiêu cực của một người tiêu dùng là sự đánh giá của con người về kết quả của hành vi đó (Ajzen \& Fishbein, 1975). Ở Thuyết TRA và TPB cũng đã chứng minh rằng Thái độ là nhân tố đặt biệt quan trọng ảnh hưởng trực tiếp đến hành vi ý định và nó hoàn toàn được kiểm chứng qua rất nhiều bài nghiên cứu khác nhau. Tác giả (Trang, 2018) dựa trên bài nghiên cứu của (Thoa, 2017) cho rằng, thái độ của người tiêu dùng đến sản phẩm xe máy điện sẽ bao gồm: sự đánh giá về hình thức XMĐ, độ an toàn, giá cả, sản phẩm có thân thiện với môi trường. Ngoài ra, một nghiên cứu khác của (Huang \& Ge, 2019) liên quan đến thái độ của người tiêu dùng là ủng hộ việc đất nước đưa ra nhiều chính sách khuyến khích người dân mua xe điện.

Giả thuyết H2: Thái độ có tác động cùng chiều (+) đến ý định mua xe máy điện Vinfast của người dân trên địa bàn TP.HCM

\subsubsection{Nhận thức kiểm soát hành vi}

Theo (Ajzen, 1991), Nhận thức kiểm soát hành vi là thể hiện nhận thức về việc dễ thực hiện hoặc khó thực hiện khi thực hiện một hành vi nhất định. Nhận thức kiểm soát hành vi là nhận thức của người tiêu dùng về việc thực hiện một hành vi nào đó, thang đo Nhận thức hành vi có tác động mạnh đến ý định sử dụng xe điện hai bánh tại Hà Nội (Thuy \& Hong, 2019). Bài nghiên cứu của (Huang \& Ge, 2019) cũng cho rằng Nhận thức kiểm soát hành vi trong trường hợp này là nhận thức mức độ dễ dàng hoặc khó khăn về các hành vi mua xe điện, ngoài ra kết quả nghiên cứu chỉ ra rằng người tiêu dùng sẽ sẵn sàng mua xe máy điện hơn nếu họ có khả năng mua và sự tự tin để mua chúng.

Giả thuyết H3: Nhận Thức kiểm soát hành vi tác động cùng chiều (+) đến ý định mua xe máy điện Vinfast của người dân trên địa bàn TP.HCM.

\subsubsection{Sụ hấp dẫn của phương tiện khác}

Phương tiện khác mà tác giả nhắc đến ở đây chính là xe máy truyền thống. Ở nghiên cứu của (Chen \& Chao, 2010) yếu tố Thói quen sử dụng phương tiện cá nhân đối với ý định sử dụng 27 phương tiện công cộng ở thành phố Kaohsiung, Đài Loan chiếm $65 \%$, xe hơi chiếm $19 \%$. Tác giả nhận thấy VN cũng có trường hợp tương tự, phương tiện cá nhân vẫn được chiếm đến $80 \%$ nhu cầu di chuyển, trong đó phương 
tiện công cộng chỉ chiếm từ 20\%-25\% (Tramoc, 2016). Chính vì vậy thay đổi thói quen sử dụng xe máy truyền thống cần nhiều thời gian hơn. Nghiên cứu của $($ Dung, 2012) chỉ ra rằng, xe máy truyền thống có một số thuộc tính tốt hơn việc dùng các phương tiện thân thiện với môi trường như tốc độ hơn, công suất mạnh hơn, đi được đoạn đường dài hơn, nhanh chóng nạp lại nhiên liệu v.v đây là bất lợi lớn đến ý định dùng tàu điện ngẩm ở TP.HCM. Vì thế, tác giả quyết định để nhân tố Sự hấp dẫn của phương tiện khác vào đề tài này nhằm kiểm định sự tác động ít nhiều đến ý định mua xe máy điện Vinfast.

Giả thuyết H4: Sự hấp dẫn của phưong tiện khác tác động nghịch chiều (-) đến ý định mua xe máy điện Vinfast của nguời dân trên địa bàn TP.HCM

\subsubsection{Chuẩn chủ quan}

Một bài nghiên cứu về ý định sử dụng xe điện trong tương lai của người dân Kaohiung (Chen \& Chao, 2010) đưa ra mức độ ảnh hưởng từ ba nhóm đối tượng chính là người quan trọng đối với cá nhân được khảo sát, ý kiến từ cộng đồng mạng xã hội và các chính sách khuyến khích của chính quyền. Trong nhóm ba đối tượng chính được đề cập trong nghiên cứu, tác giả đề xuất thêm người có sức ảnh hưởng như người nổi tiếng, người truyền cảm hứng, thần tượng của bản thân cũng có thể tác động đến ý định mua xe máy điện Vinfast. Chuẩn chủ quan khi được nhắc đển ở đây còn có thể là do các doanh nghiệp tác động trực tiếp hoặc gián tiếp đến hành vi người tiêu dùng như hành động tiếp thị của người bán hàng, chính sách khuyên mãi hấp dẫn, dịch vụ hậu mãi khi mua (Kotler \& cộng sự, 2014).

Giả thuyết H5: Chuẩn chủ quan tác động cùng chiều (+) đến ý định mua xe máy điện Vinfast của người dân trên địa bàn TP.HCM

\subsubsection{Chính sách khuyến mãi}

Trong bài nghiên cứu của (Liao \& cộng sự, 2016) khi nhận xét về các công cụ chính sách khác nhau có thể thúc đẩy được khả năng sử dụng xe máy điện, có ba chính sách được thử nghiệm và hiệu quả trong các nghiên cứu trước đây: Thứ nhất là chính sách giá bao gồm giảm giá một lần, giảm thuế mua hàng (Hess \& cộng sự, 2012), (Potoglou \& Kanaroglou, 2007) và giảm giá mua (Glerum \& cộng sự, 2014). Thứ hai là chính sách giảm chi phí sử dụng bao gồm giảm thuế hằng năm (Chorus, 2013), (Hackbarth \& Madlenner, 2013), (Hoen \& Koetse, 2014) và cuối cùng là chính sách phi tài chính (Hackbarth \& Madlenner, 2013). Phần kết luận của tác giả (Liao \& cộng sự, 2016) nhấn mạnh rằng chính sách khuyến mãi là một trong những yếu tố tác động đáng kể đến ý định lựa chọn xe máy điện nên tác giả quyết định đưa yếu tố này vào bài nghiên cứu của mình để kiếm chứng. Một nghiên cứu khác của (Huang \& $\mathrm{Ge}, 2019)$ cho rằng các biện pháp chính sách khuyến khích tiền tệ có tác động tích cực đến ý định mua xe máy điện của người dân Trung Quốc.

Giả thuyết H6: Chính sách khuyến mãi tác động cùng chiều (+) đến ý định mua xe máy điện Vinfast của người dân trên địa bàn TP.HCM

Bên dưới là mô hình đề xuất bao gồm 6 nhân tố được tác giả đưa vào là: (1) Nhận thức về môi trường, (2) Thái độ, (3) Nhận thức kiểm soát hành vi, (4) Sự hấp dẫn của phương tiện khác, (5) Chuẩn chủ quan và cuối cùng là (6) Chính sách khuyến mãi.

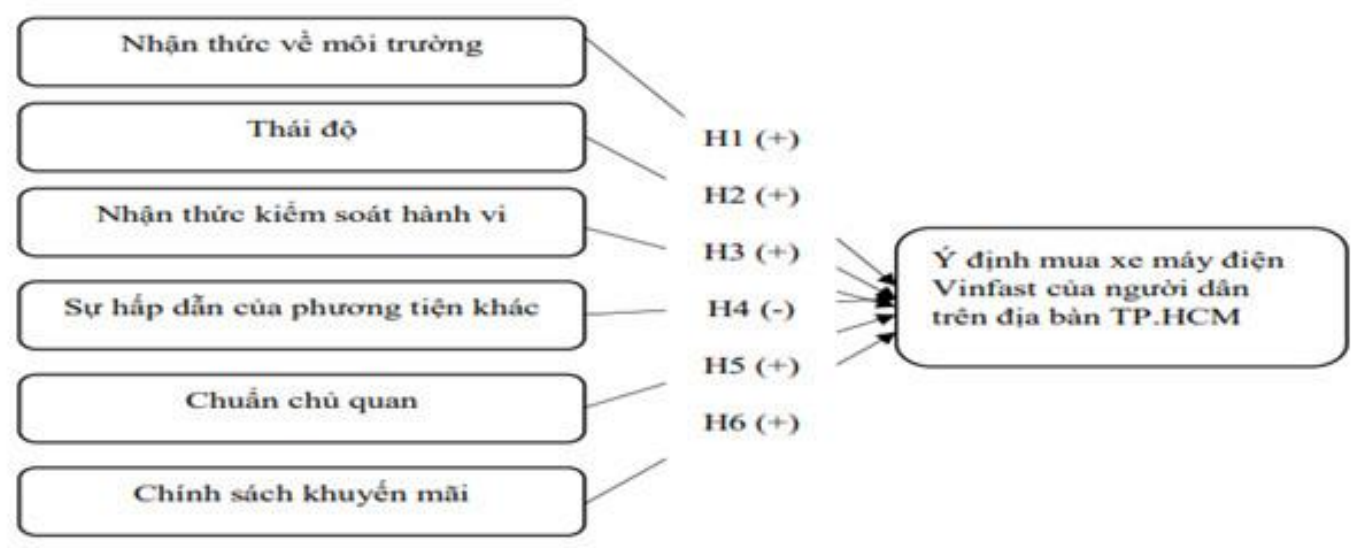

Hình 2.3 Mô hình nghiên cứu đề xuất

Nguồn: Tác giả tổng hợp 


\section{PHƯƠNG PHÁP NGHIÊN CÚU}

Phương pháp nghiên cứu được chia thành 3 giai đoạn chính: giai đoạn một là nghiên cứu sơ bộ, giai đoạn hai là nghiên cứu chính thức và giai đoạn ba là xử lý dữ liệu rồi kết luận.

Giai đoạn 1: Nghiên cứu sơ bộ bằng cách tham khảo ý kiến từ các chuyên gia và người sử dụng cho đề tài nghiên cứu từ đó có sự điều chỉnh, bổ sung, xây dựng thang đo và mô hình phù hợp với đề tài nghiên cứu. Giai đoạn này được thực hiện bằng phương pháp nghiên cứu định tính sử dụng phương pháp thu thập dữ liệu từ các bài nghiên cứu có liên quan để chọn ra đề tài nghiên cứu phù hợp, mục tiêu, đối tượng nghiên cứu. Mục đích cuối cùng là chọn ra được các thang đo phù hợp với đề tài các yếu tố tác động đến ý định mua xe máy điện Vinfast của người dân trên địa bàn TP.HCM.

Giai đoạn 2: nghiên cứu chính thức được thực hiện bằng phương pháp định lượng, bằng việc tham khảo các lý thuyết nền, các bài nghiên cứu liển quan đến đề tài của tác giả để thiết lập bảng câu hỏi hoàn chỉnh được đo lường bằng thang đo Likert 5 điểm. Bảng câu hỏi sẽ bao gồm 3 phần: sàng lọc thông tin, thông tin cá nhân, nội dung khảo sát.

Giai đoạn 3: Tác giả phát ra 200 mẫu khảo sát bao gồm 2 hình thức: phát giấy khảo sát và khảo sát online. Sử dụng phương pháp lấy mẫu phi xác suất và lựa chọn ra được 154 mẫu phù hợp nhất. Sau đó tác giả tiến hành xử lý số liệu bằng SPSS 20.0 cho ra kết quả rồi dựa vào kết quả để đưa ra các hàm ý quản trị.

\subsection{Phương pháp lấy mẫu}

Theo (Hair \& cộng sự, 2009), cỡ mẫu để phân tích tối thiểu sẽ là $n=5 * 6+5 * 4+5 * 4+5 * 5+5 * 4+5 * 4=$ 135 (mẫu). Như vậy mức mẫu tối thiểu cho nghiên cứu này là 135 quan sát. Tác giả sử dụng phương pháp chọn mẫu phi xác suất để lấy mẫu và quyết định thực hiện 200 mẫu khảo sát bằng cách gửi bảng câu hỏi trực tiếp hoặc khảo sát online.

\subsection{Thang đo nghiên cứu}

Bảng 3.1 Thang đo nghiên cứu

\begin{tabular}{|c|c|c|}
\hline Nhân tố & Biến quan sát & Nguồn \\
\hline $\begin{array}{l}\text { Nhận } \\
\text { thức về } \\
\text { môi } \\
\text { trường }\end{array}$ & $\begin{array}{l}\text { MT1: Mối đe dọa từ ô nhiễm môi trường, ô nhiễm không khí ngày càng nghiêm } \\
\text { trọng } \\
\text { MT2: Bảo vệ môi trường là trách nhiệm chung của mỗi cá nhân } \\
\text { MT3: Sử dụng xe máy truyền thống nhiều làm tăng ô nhiễm môi trường ở } \\
\text { TP.HCM } \\
\text { MT4: Tôi sẽ sử dụng xe điện xanh vì tôi có thói quen sử dụng những sản phẩm } \\
\text { thân thiện với môi trường }\end{array}$ & $\begin{array}{l}\text { (Yi-Chang \& Gwo- } \\
\text { Hshiung, 1999) } \\
\text { (Trang, 2018) } \\
\text { (Dung, 2012) } \\
\text { (Thøgersen, 1999) }\end{array}$ \\
\hline Thái độ & $\begin{array}{l}\text { TĐ1: Tôi cho rằng xe máy điện Vinfast thân thiện với môi trường } \\
\text { TĐ2: Xe máy điện Vinfast có kiểu dáng thời trang, hiện đại } \\
\text { TĐ3: Tôi ủng hộ đất nước đưa ra nhiều chính sách khuyến khích người dân } \\
\text { mua xe điện } \\
\text { TĐ4: Tôi nghĩ rằng giá cả của xe máy điện Vinfast tương ứng với chất lượng } \\
\text { sản phẩm } \\
\text { TĐ5: Tôi nghĩ rằng xe máy điện Vinfast dễ sử dụng hơn các loại xe máy điện } \\
\text { khác } \\
\text { TĐ6: Các tính năng của xe máy điện Vinfast thể hiện sự mong đợi của tôi về } \\
\text { chất lượng sản phẩm }\end{array}$ & $\begin{array}{l}\text { (Thoa, 2017) } \\
\text { (Trang, 2018) } \\
\text { (Huang \& Ge, 2019) } \\
\text { (Ajzen \& Fishbein, } \\
\text { 1975) } \\
\text { (Trà, 2019) }\end{array}$ \\
\hline $\begin{array}{l}\text { Nhận } \\
\text { thức } \\
\text { kiểm soát } \\
\text { hành vi }\end{array}$ & $\begin{array}{l}\text { KSHV1: Tôi quan tâm thương hiệu xe máy điện Vinfast hơn là thương hiệu xe } \\
\text { máy điện khác } \\
\text { KSHV2: Mua hay không mua xe máy điện Vinfast là do tôi quyết định } \\
\text { KSHV3: Tài chính của tôi có thể sở hữu được xe máy điện Vinfast } \\
\text { KSHV4: Tôi nghĩ xe máy điện Vinfast dễ sử dụng }\end{array}$ & $\begin{array}{l}\text { (Ajzen, 1999), } \\
\text { (Thuy \& Hong, } \\
\text { 2019), (Ajzen \& } \\
\text { Fishbein, 1975) }\end{array}$ \\
\hline $\begin{array}{l}\text { Sữ hấp } \\
\text { dẫn của } \\
\text { phương } \\
\text { tiện khác }\end{array}$ & $\begin{array}{l}\text { SHD1: Tôi nghĩ rằng xe máy truyền thống bền hơn xe máy điện Vinfast } \\
\text { SHD2: Xe máy truyền thống nhanh chóng nạp lại nguyên liệu hơn xe SHD3: } \\
\text { máy điện Vinfast }\end{array}$ & $\begin{array}{l}\text { (Dung, 2012) } \\
\text { (Chen \& Chao, } \\
\text { 2010) }\end{array}$ \\
\hline
\end{tabular}




\begin{tabular}{|c|c|c|}
\hline & $\begin{array}{l}\text { SHD4: Xe máy truyền thống có quãng đường di chuyển xa hơn xe máy điện } \\
\text { Vinfast } \\
\text { SHD5: Tôi nghĩ rằng chi phí sử dụng xe máy truyền thống thấp hơn so với xe } \\
\text { máy điện } \\
\text { SHD6: Tôi đã quen với việc sử dụng xe máy truyền thống hằng ngày }\end{array}$ & \\
\hline $\begin{array}{l}\text { Chuẩn } \\
\text { chủ quan }\end{array}$ & $\begin{array}{l}\text { CCQ1: Tôi quan tâm đến xe máy điện Vinfast vì mọi người xung quanh tôi } \\
\text { cũng sử dụng chúng } \\
\text { CCQ2: Tôi quan tâm xe máy điện Vinfast vì người thân, bạn bè, đồng nghiệp } \\
\text { khuyên tôi nên sử dụng xe máy điện Vinfast } \\
\text { CCQ3: Quyết định sử dụng xe máy điện Vinfast của tôi có thể bị ảnh hưởng } \\
\text { bởi lời khuyên, cảm nhận cá nhân trên mạng xã hội } \\
\text { CCQ4: Tôi quan tâm xe máy điện Vinfast vì người nổi tiếng mà tôi yêu thích } \\
\text { khuyên tôi nên sử dụng. }\end{array}$ & $\begin{array}{l}\text { (Ajzen, 1991) } \\
\text { (Huang \& Ge, } \\
\text { 2019), (Kotler \& } \\
\text { cộng sự, 2014), } \\
\text { (Chen \& Chao, } \\
\text { 2010), (Lim \& cộng } \\
\text { sự, 2017) }\end{array}$ \\
\hline $\begin{array}{l}\text { Chính } \\
\text { sách } \\
\text { khuyến } \\
\text { mãi }\end{array}$ & $\begin{array}{l}\text { CSKM1: Tôi nghĩ rằng Nhà nước nên có nhiều chính sách giảm thuế khi mua } \\
\text { xe máy điện } \\
\text { CSKM2: Tôi nghĩ rằng Vinfast nên miễn giảm chi phí đậu xe dài hạn ở các khu } \\
\text { vực thuộc địa bàn của Vinfast. } \\
\text { CSKM3: Tôi nghĩ rằng Vinfast nên có chính sách cho mua xe điện trả góp hợp } \\
\text { lý } \\
\text { CSKM4: Tôi nghĩ Vinfast nên chú trọng các chính sách ưu đãi bảo hiểm khi } \\
\text { mua xe máy điện. }\end{array}$ & $\begin{array}{l}\text { (Liao \& cộng sự, } \\
\text { 2016), (Glerum \& } \\
\text { cộng sự, 2014), } \\
\text { (Hackbarth \& } \\
\text { Madlenner, 2013), } \\
\text { (Huang \& Ge, 2019) }\end{array}$ \\
\hline $\begin{array}{c}\text { Ý định } \\
\text { mua }\end{array}$ & $\begin{array}{l}\text { YD1: Mua xe máy điện Vinfast là sự lựa chọn đầu tiên nếu tôi mua xe máy } \\
\text { điện } \\
\text { YD2: Tôi có ý định mua xe máy điện Vinfast trong tương lai } \\
\text { YD3: Tôi sẽ giới thiệu xe máy điện Vinfast cho bạn bè, người thân nếu họ có } \\
\text { ý định. }\end{array}$ & $\begin{array}{l}\text { (Lu \& cộng sự, } \\
\text { 2014), (Huang \& } \\
\text { Ge, 2019), (Ajzen \& } \\
\text { Fishbein, 1975), } \\
\text { (Ajzen, 2002) }\end{array}$ \\
\hline
\end{tabular}

\section{KẾT QUẢ NGHIÊN CÚU}

Nguồn: Tác giả tổng hơp

\section{1. Đặc điểm mẫu khảo sát}

Sau khi xác định phương pháp chọn mẫu phi xác suất để thực hiện khảo sát đã được tác giả phát ra 200 mẫu khảo sát. Kết quả thu về được 153 mẫu khảo sát hợp lệ để đưa vào các bước phân tích tiếp theo.

Bảng 4.1 Đặc điểm mẫu nghiên cứu

\begin{tabular}{|c|c|c|c|}
\hline \multicolumn{2}{|c|}{ Đặc điểm của mẫu (cỡ mẫu n=153) } & Số lượng (người) & Tỷ lệ (\%) \\
\hline \multirow{4}{*}{ Giới tính } & Nam & 91 & 59.5 \\
\cline { 2 - 4 } & Nữ & 62 & 40.5 \\
\cline { 2 - 4 } & Tổng & 153 & 100.0 \\
\hline \multirow{4}{*}{ Độ tuổi } & Dưới 18 tuổi & 33 & 21.6 \\
\cline { 2 - 4 } & Từ 18 đến 23 tuổi & 75 & 49.0 \\
\cline { 2 - 4 } & Từ 24 đến 30 tuổi & 35 & 22.9 \\
\cline { 2 - 4 } & Trên 30 tuổi & 10 & 6.5 \\
\cline { 2 - 4 } & Tổng & 153 & 100.0 \\
\hline \multirow{4}{*}{ Trình độ học vấn } & Dưới trung học phổ thông & 38 & 24.8 \\
\cline { 2 - 4 } & Trung học phổ thông & 69 & 45.1 \\
\cline { 2 - 4 } & Đại học/ cao đẳng & 30 & 19.6 \\
\cline { 2 - 4 } & Sau đại học & 16 & 10.5 \\
\cline { 2 - 4 } & Tổng & 153 & 100.0 \\
\hline Nghề nghiệp & Học sinh/ sinh viên & 43 & 28.1 \\
\hline
\end{tabular}



TRÊN ĐİA BÀN TP.HCM

\begin{tabular}{|c|c|c|c|}
\hline \multirow{4}{*}{} & Nhân viên văn phòng & 76 & 49.7 \\
\cline { 2 - 4 } & Lao động tự do & 19 & 12.4 \\
\cline { 2 - 4 } & Khác & 15 & 9.8 \\
\cline { 2 - 4 } & Tổng & 153 & 100.0 \\
\hline \multirow{5}{*}{ Thu nhập } & Dưới 3 triệu & 42 & 27.5 \\
\cline { 2 - 4 } & Từ 3 triệu - dưới 7 triệu & 28 & 18.3 \\
\cline { 2 - 4 } & 7 triệu - dưới 10 triệu & 51 & 33.3 \\
\cline { 2 - 4 } & Trên 10 triệu & 32 & 20.9 \\
\cline { 2 - 4 } & Tổng & 153 & 100.0 \\
\hline
\end{tabular}

\subsection{Kết quả đánh giá trung bình của các nhân tố}

Nguồn: Dũ liệu phân tích của tác giả

Bảng 4.2 Kết quả trung bình nhân tố

\begin{tabular}{|c|c|c|c|c|c|c|c|c|c|c|c|}
\hline & Mean & & Mean & & Mean & & Mean & & Mean & & Mean \\
\hline $\begin{array}{l}\text { Mã } \\
\text { hoá }\end{array}$ & MT & $\begin{array}{l}\text { Mã } \\
\text { hoá }\end{array}$ & ТĐ & Mã hoá & KSHV & Mã hoá & SHD & $\begin{array}{l}\text { Mã } \\
\text { hoá }\end{array}$ & CQ & $\begin{array}{l}\text { Mã } \\
\text { hoá }\end{array}$ & CSKM \\
\hline MT1 & 3.67 & TĐ1 & 3.61 & KSHV1 & 3.49 & SHD1 & 3.14 & CQ1 & 3.49 & $\begin{array}{c}\text { CSK } \\
\text { M1 }\end{array}$ & 3.83 \\
\hline MT2 & 3.69 & TĐ2 & 3.48 & KSHV2 & 3.50 & SHD2 & 3.20 & CQ2 & 3.42 & $\begin{array}{c}\text { CSK } \\
\text { M2 }\end{array}$ & 3.73 \\
\hline MT3 & 3.67 & TĐ3 & 3.58 & KSHV3 & 3.42 & SHD3 & 3.22 & CQ3 & 3.46 & $\begin{array}{c}\text { CSK } \\
\text { M3 }\end{array}$ & 3.69 \\
\hline \multirow{3}{*}{ MT4 } & \multirow{3}{*}{3.71} & TĐ4 & 3.55 & \multirow{3}{*}{ KSHV4 } & \multirow{3}{*}{3.50} & SHD4 & 3.08 & \multirow{3}{*}{ CQ4 } & \multirow{3}{*}{3.50} & \multirow{3}{*}{$\begin{array}{c}\text { CSK } \\
\text { M4 }\end{array}$} & \multirow{3}{*}{3.69} \\
\hline & & TĐ5 & 3.48 & & & & 00 & & & & \\
\hline & & TĐ6 & 3.57 & & & SHDડ & 2.99 & & & & \\
\hline
\end{tabular}

Nguồn: Dũ liệu phân tích của tác giả

Kết quả của bảng 4.2 ta thấy rằng các giá trị trung bình giao động từ 3.42 đến 3.83 được đánh giá khá tốt

\subsection{Kết quả phân tích độ tin cậy thang đo Cronbach's Alpha}

Bảng 4.3 Phân tích kết quả Cronbach's alpha

\begin{tabular}{|c|c|c|c|c|}
\hline STT & Thang đo & Mã hoá & Số biến quan sát & $\begin{array}{c}\text { Hệ số Cronbach's Alpha nếu } \\
\text { loại biến }\end{array}$ \\
\hline 1 & Nhận thức về môi trường & MT & 4 & 0.775 \\
\hline 2 & Thái độ & TĐ & 6 & 0.904 \\
\hline 3 & Nhận thức kiểm soát hành vi & KSHV & 4 & 0.883 \\
\hline 4 & $\begin{array}{c}\text { Sự hấp dẫn của phương tiện } \\
\text { khác }\end{array}$ & SHD & 5 & 0.909 \\
\hline 5 & Chuẩn chủ quan & CQ & 4 & 0.922 \\
\hline 6 & Chính sách khuyến mãi & CSKM & 4 & 0.827 \\
\hline 7 & Ý định mua & YD & 3 & 0.743 \\
\hline
\end{tabular}

Nguồn: Dũ liệu phân tích của tác giả

Từ bảng 4.3 ta thấy các hệ số Cronbach's Alpha khá cao đều > 0.6, trong đó biến TĐ, SHD, CCQ được cho rằng các thang đo này đo lường rất tốt. Các biến trong thang đo đều được tiếp tục thực hiện cho các bước tiếp theo. 


\subsection{Kết quả phân tích nhân tố EFA}

Bảng 4.4 Phân tích nhân tố EFA

\begin{tabular}{|c|c|c|c|c|c|c|c|c|c|c|c|}
\hline \multicolumn{12}{|c|}{ Các biến độc lập } \\
\hline $\begin{array}{l}\text { Mã } \\
\text { hoá }\end{array}$ & ТÐ & Mã hoá & SHD & $\begin{array}{l}\text { Mã } \\
\text { hoá }\end{array}$ & CQ & Mã hoá & $\begin{array}{c}\text { KSH } \\
\text { V }\end{array}$ & Mã hoá & CSKM & $\begin{array}{l}\text { Mã } \\
\text { hoá }\end{array}$ & MT \\
\hline TĐ1 & 0.851 & SHD1 & 0.817 & CQ1 & 0.901 & KSHV1 & 0.780 & CSKM1 & 0.760 & MT1 & 0.738 \\
\hline ТĐ2 & 0.838 & SHD2 & 0.842 & CQ2 & 0.859 & KSHV2 & 0.867 & CSKM2 & 0.730 & MT2 & 0.775 \\
\hline ТĐ3 & 0.643 & SHD3 & 0.809 & CQ3 & 0.846 & KSHV3 & 0.873 & CSKM3 & 0.799 & MT3 & 0.721 \\
\hline TÐ4 & 0.749 & SHD4 & 0.799 & \multirow{3}{*}{ CQ4 } & \multirow{3}{*}{0.917} & \multirow{3}{*}{ KSHV4 } & \multirow{3}{*}{0.801} & \multirow{3}{*}{ CSKM4 } & \multirow{3}{*}{0.807} & \multirow{3}{*}{ MT4 } & \multirow{3}{*}{0.819} \\
\hline TĐ5 & 0.741 & \multirow{2}{*}{ SHD5 } & 0010 & & & & & & & & \\
\hline TĐ6 & 0.894 & & 0.010 & & & & & & & & \\
\hline KMO & \multicolumn{11}{|c|}{$0.5 \leq 0.817 \leq 1$} \\
\hline Sig & \multicolumn{11}{|c|}{$0.000<0.05$} \\
\hline \multicolumn{4}{|c|}{ Tổng phương sai trích } & \multicolumn{8}{|c|}{$71.571 \%>50 \%$} \\
\hline \multicolumn{12}{|c|}{ Biến phụ thuộc } \\
\hline \multirow[t]{2}{*}{$\begin{array}{l}\text { Mã } \\
\text { hoá }\end{array}$} & YD1 & YD2 & YD3 & & & & & & & & \\
\hline & 0.825 & 0.817 & 0.798 & & & & & & & & \\
\hline KMO & \multicolumn{11}{|c|}{$0.5 \leq 0.688 \leq 1$} \\
\hline Sig & \multicolumn{11}{|c|}{$0.000<0.05$} \\
\hline \multicolumn{4}{|c|}{ Tổng phương sai trích } & \multicolumn{8}{|c|}{$66.136 \%>50 \%$} \\
\hline
\end{tabular}

Nguồn: Dũ liệu phân tích của tác giả

Kết quả phân tích bảng 4.4 ta thấy rằng cả hai biến đều đạt giá trị hội tụ và giá trị phân biệt được chấp nhận, dữ liệu nghiên cứu phù hợp với việc phân tích EFA khi các hệ số KMO của biến độc lập là $0.817(0.5 \leq$ $\mathrm{KMO} \leq 1)$ và hệ số $\mathrm{KMO}$ của biến phụ thuộc là $0.688(0.5 \leq \mathrm{KMO} \leq 1)$. Ở kiểm định Bartlett có hệ số sig. $=0.000(<0.05)$ để các biến quan sát có sự tương quan với nhau về tổng thể. Tổng phương sai trích của biển độc lập $=71.571 \%(>50 \%)$. Điều này cho 6 biến độc lập của tổng phương sai trích giải thích được $71.571 \%$ biến thiên của dữ liệu quan sát. Còn đối với biến phụ thuộc có tổng phương sai trích là $66.136 \%$ (>50\%) biến thiên của dữ liệu quan sát.

Như vậy các giả thuyết trong mô hình đề xuất của tác giả được giữ nguyên như sau:

H1: Nhận thức về môi trường tác động cùng chiều đến ý định mua xe máy điện Vinfast

H2: Thái độ tác động cùng chiều đến ý định mua xe máy điện Vinfast

H3: Nhận thức kiểm soát hành vi tác động cùng chiều đến ý định mua xe máy điện Vinfast

H4: Sự hấp dẫn của phương tiện khác tác động nghịch chiều đến ý định mua xe máy điện Vinfast

H5: Chuẩn chủ quan tác động cùng chiều đến ý định mua xe máy điện Vinfast

H6: Chính sách khuyến mãi tác động cùng chiều đến ý định mua xe máy điện Vinfast.

\subsection{Kiểm định tương quan}

Bảng 4.5 Bảng kết quả tương quan Pearson

\begin{tabular}{|l|c|c|}
\hline \multicolumn{1}{|c|}{ Yếu tố cần đánh giá } & Hệ số Sig & Hệ số tương quan Pearson \\
\hline MT - Nhận thức về môi trường & 0.000 & 0.368 \\
\hline TĐ - Thái độ & 0.000 & 0.564 \\
\hline KSHV - Nhận thức kiểm soát hành vi & 0.000 & 0.445 \\
\hline SHD - Sự hấp dẫn của phương tiện khác & 0.000 & -0.602 \\
\hline
\end{tabular}




\begin{tabular}{|l|l|l|}
\hline CQ - Chuẩn chủ quan & 0.009 & 0.402 \\
\hline CSKM - Chính sách khuyến mãi & 0.000 & 0.476 \\
\hline
\end{tabular}

Nguồn: Dũ liệu phân tích của tác giả

Các yếu tố như MT, TĐ, KSHV, SHD, CQ, CSKM có quan hệ chặt chẽ với "Ý định mua" vì có hệ số sig $<0.05$. Ta kết luận rằng $\mathrm{MT}, \mathrm{T}, \mathrm{KSHV}, \mathrm{SHD}, \mathrm{CQ}, \mathrm{CSKM}$ có tương quan với yếu tố "Ý định mua".

\subsection{Kết quả hồi quy}

Bảng 4.6 Kết quả phân tích mô hình hồi quy

\begin{tabular}{|c|c|c|c|c|c|c|}
\hline \multirow{2}{*}{ Mô hình } & \multicolumn{2}{|c|}{ Hệ số chưa chuẩn hoá } & \multirow{2}{*}{$\begin{array}{c}\begin{array}{c}\text { Hệ số } \\
\text { chuẩn hoá }\end{array} \\
\text { Beta }\end{array}$} & \multirow{2}{*}{$\begin{array}{c}\text { Mức ý } \\
\text { nghĩa (Sig) }\end{array}$} & \multicolumn{2}{|c|}{ Đa cộng tuyến } \\
\hline & B & $\begin{array}{l}\text { Sai số } \\
\text { chuâ̂n }\end{array}$ & & & Dung sai & VIF \\
\hline (Tần số) & 1.135 & .353 & & .002 & & \\
\hline MT & .233 & .055 & .220 & .000 & .929 & 1.076 \\
\hline $\mathrm{TÐ}$ & .237 & .053 & .264 & .000 & .711 & 1.406 \\
\hline KSHV & .135 & .044 & .170 & .002 & .836 & 1.196 \\
\hline SHD & -.146 & .028 & -.301 & .000 & .734 & 1.363 \\
\hline CQ & .110 & .035 & .169 & .002 & .877 & 1.140 \\
\hline CSKM & .133 & .045 & .168 & .004 & .781 & 1.280 \\
\hline \multicolumn{7}{|c|}{$\begin{array}{l}\mathrm{R}^{2} \text { hiệu chỉnh: } 0.619 \\
\text { Hệ số Durbin -Watson: } 2.100 \\
\text { Giá trị kiểm định F: } 42.186 \\
\text { Phương trình hồi quy: } \mathrm{YD}=0.220 * \mathrm{MT}+0.264 * \mathrm{~T} Đ+0.170 * \mathrm{KSHV}+(-0.301) * \mathrm{SHD}+0.169 * \mathrm{CQ}+ \\
0.168 * \mathrm{CSKM}\end{array}$} \\
\hline
\end{tabular}

Nguồn: Dũ liệu phân tích của tác giả

Từ bảng 4.6 ta thấy rằng khi phân tích phương sai ANOVA kết quả kiểm định $\mathrm{F}$ có giá trị Sig rất nhỏ (Sig. $=0.000<0.05)$, mô hình hồi quy tuyến tính được cho là phù hợp với tổng thể. Ngoài ra hệ số $\mathrm{R}^{2}$ hiệu chỉnh $=0.619$ nằm ở mô hình hồi quy đa biến, 6 biến độc lập được đưa vào ảnh hưởng $61.9 \%$ sự thay đổi của biến phụ thuộc, còn lại $38.1 \%$ là do các biến ngoài mô hình và sai số ngẫu nhiên.

Hệ số Sig của 6 biến độc lập đều < 0.05 , các biến độc lập này đều thỏa điều kiện và có ý nghĩa trong mô hình. Không có biến nào bị loại bỏ. Hệ số VIF đều < 2 nên không bị xảy ra hiện tượng đa cộng tuyến.

Tóm lại, thứ tự yếu tố ảnh hưởng đến ý định mua xe máy điện Vinfast của người dân trên địa bàn Thành phố Hồ Chí Minh được sắp xếp từ cao đến thấp như sau: nhân tố Sự hấp dẫn của phương tiện khác $(\beta=$ $0.301)$ có tác động mạnh nhất và có quan hệ ngược chiều (dấu -). Nhân tố Thái độ $(\beta=0.264)$ có tác động mạnh thứ hai và quan hệ cùng chiều (dấu +$)$. Nhân tố Nhận thức về môi trường $(\beta=0.220)$ có tác động mạnh thứ ba và quan hệ cùng chiều (dấu + ). Nhân tố Nhận thức kiểm soát hành vi $(\beta=0.170)$ có tác động mạnh thứ tư và quan hệ cùng chiều (dấu + ). Nhân tố Chuẩn chủ quan $(\beta=0.169)$ có tác động mạnh thứ năm và quan hệ cùng chiều (dấu + ). Và nhân tố cuối cùng, Chính sách khuyến mãi $(\beta=0.168)$ có tác động thấp nhất và quan hệ cùng chiều (dấu + ). Phương trình hồi quy chuẩn hoá có dạng: $\mathrm{YD}=0.220^{*} \mathrm{MT}+$ $0.264 * \mathrm{~T} Đ+0.170 * \mathrm{KSHV}+(-0.301) * \mathrm{SHD}+0.169 * \mathrm{CQ}+0.168 * \mathrm{CSKM}$.

\section{HÀM Ý QUẢN TRI VÀ KẾT LUẬN}

\subsection{Kết luận}

Tác giả đã hoàn thành mục tiêu nghiên cứu đề tài bao gồm hệ thống lại các cơ sở lý thuyết về ý định hành vi và xác định được các yếu tố có ảnh hưởng ít nhiều đến ý định mua xe máy điện của người dân trên địa bàn TP.HCM. Từ đó, tác giả đề xuất một số hàm ý quản trị giúp nâng cao sự lựa chọn của khách hàng, là tài liệu tham khảo cho các nghiên cứu có liên quan. 
Nắm rõ được mục tiêu nghiên cứu của đề tài, tác giả đã tổng hợp thông tin từ các cơ sở lý thuyết nền như TRA, TPB, TAM và các bài nghiên cứu có liên quan để xem xét các nhân tố có thể đo lường được, tác giả đã xác định được 6 nhân tố ảnh hưởng đến ý định mua xe máy điện Vinfast của người dân trên địa bàn TP.HCM bao gồm: Nhận thức về môi trường, Thái độ, Nhận thức kiểm soát hành vi, Sự hấp dẫn của phương tiện khác, Chuẩn chủ quan và cuối cùng là Chính sách khuyến mãi với 27 biến quan sát. Qua quá trình phân tích dữ liệu SPSS, tác giả kết luận rằng 6 yếu tố này đều có sự tác động đến ý định mua xe máy điện Vinfast của người dân trên địa bàn Thành phố Hồ Chí Minh theo thứ tự như sau: nhân tố Sự hấp dẫn của phương tiện khác $(\beta=-0.301)$ có tác động mạnh nhất, nhân tố Thái độ $(\beta=0.264)$ có tác động mạnh thứ hai, nhân tố Nhận thức về môi trường $(\beta=0.220)$ có tác động mạnh thứ ba, nhân tố Nhận thức kiểm soát hành vi $(\beta=$ $0.170)$ có tác động mạnh thứ tư, nhân tố Chuẩn chủ quan $(\beta=0.169)$ có tác động mạnh thứ năm và nhân tố cuối cùng, Chính sách khuyến mãi $(\beta=0.168)$ có tác động thấp nhất trong đề tài nghiên cứu về ý định mua xe máy điện của người dân trên địa bàn TP.HCM.

\subsection{Hàm ý quản trị}

Thứ nhất, xét theo góc độ bài nghiên cứu của (Dung, 2012) đã chỉ ra rằng xe máy truyền thống vẫn tiện ích hơn việc sử dụng phương tiện thân thiện với môi trường như tốc độ hơn, công suất hơn, đi được đoạn đường dài hơn, v.v làm cản trở ý định sử dụng phương tiện thân thiện với môi trường. Nhưng đối với kết quả nghiên cứu của tác giả đã chứng minh ngược lại, cụ thể đối với nhân tố Sự hấp dẫn của phương tiện khác $(\beta=-0.301)$ tức nghĩa là người thực hiện khảo sát không đồng ý với các biến quan sát và biến này có tác động mạnh nhất đến ý định mua xe máy điện của người dân trên địa bàn TP.HCM, khi cho rằng yếu tố môi trường. Trong đó kết quả nghiên cứu cho thấy rằng biến quan sát SHD3 "Sau mỗi lần nạp nguyên liệu, xe máy truyền thống đi được cung đường dài hơn xe máy điện" có giá trị Mean $=3.22$ cao nhất ngược lại thấp nhất là biến quan sát SHD5 "Tôi đã quen với việc sử dụng xe máy truyền thống hằng ngày" có giá trị Mean $=2.99$. Từ đó tác giả đưa ra một số hàm ý quản trị như sau: Người tiêu dùng ngày nay có xu hướng quan tâm nhiều hơn đến vấn đề môi trường vì vậy cần phải đẩy mạnh công tác giáo dục tuyên truyền về hành vi tiêu dùng nhanh, tăng cường nhận thức về lợi ích của việc tiêu dùng xanh. Việc tạo ra xu hướng và thói quen tiêu dùng xanh rất cần sự hỗ trợ từ chính phủ và sự tham gia của các doanh nghiệp. Về lâu dài, chính phủ Việt Nam nên có sự học hỏi kế thừa phù hợp các dự án "Môi trường" từ các quốc gia trên thế giới như là Ngày Môi trường Thế giới của Liên Hiệp Quốc, Ngày Trái Đất 2021, v.v nhờ sự nỗ lực tuyên truyền của nhà nước và cộng đồng.

Thứ hai, đối với nhân tố Thái độ $(\beta=0.264)$ có tác động thứ nhì đến ý định mua xe máy điện của người dân trên địa bàn TP.HCM. Kết quả này phù hợp với mô hình TPB khi cho rằng yếu tố Thái độ là yếu tố đặc biệt quan trọng trong việc ra ý định (Ajzen \& Fishbein, 1975), các kết quả thu về của biến Thái độ đa số đều có các nhận xét tích cực đến các dòng sản phẩm xe máy điện của Vinfast, không có biến quan sát nào bị loại bỏ. Trong đó kết quả nghiên cứu cho thấy rằng biến quan sát TĐ1 "Tôi cho rằng xe máy điện Vinfast thân thiện với môi trường", có giá trị Mean = 3.61 cao nhất, thấp nhất là biến quan sát TĐ2 "Xe máy điện Vinfast có kiểu dáng thời trang, hiện đại”, TĐ5 "Tôi nghĩ rằng xe máy điện Vinfast có độ bền hơn các loại xe máy điện khác" khi cả hai có giá trị Mean $=3.48$. Tác giả đề xuất hàm ý quản trị như sau: để người tiêu dùng có thể gia tăng thái độ tích cực đối với xe máy điện VF, đối với doanh nghiệp Vinfast nên tập trung tạo ra nhiều mẫu mã sản phẩm thời trang, cập nhật các tính năng động cơ công nghệ tiên tiến và đưa ra nhiều chiến lược giá thu hút khác hơn. Còn đối với nhà kinh doanh bán lẻ nên chú trọng cách tiếp thị sản phẩm lồng ghép với yếu tố môi trường. Nhìn tổng quan mà nói Vinfast khá thành công trong việc marketing thương hiệu gắn liền với yếu tố môi trường và nên duy trì chiến lược tiếp thị này trong tương lai.

Thứ ba, theo sau nhân tố Thái độ là nhân tố Nhận thức về môi trường có $(\beta=0.220)$. Trong đó kết quả nghiên cứu cho thấy rằng biến quan sát MT4 có giá trị Mean $=3.71$ "Tôi sẽ sử dụng xe điện xanh vì tôi có thói quen sử dụng những sản phẩm thân thiện với môi trường" khá giống với chứng minh của (Thogersen, 1999) khi cho rằng hành vi thân thiện với môi trường có xu hướng lây lan sang nhiều lĩnh vực khác. Thấp nhất là biến quan sát MT1 "Ô nhiễm môi trường, ô nhiễm không khí ngày càng nghiêm trọng đang là mối đe dọa của cả thế giới" và MT3 "Sử dụng xe máy truyền thống nhiều làm tăng ô nhiềm môi trường ở TP.HCM", cả hai có giá trị Mean = 3.67. Như vậy giá trị trung bình từ MT1 đến MT4 không chênh lệch nhau nhiều từ 3.67 đến 3.71 , điều này cho thấy rằng người khảo sát đồng tình với các biến quan sát và có nhận thức được tình trạng ô nhiễm môi trường, ô nhiễm không khí ngày càng đặc biệt nghiêm trọng đang diền ra tại Việt Nam. Các nhà quản lý nên đồng hành cùng Chính quyền nhà nước đẩy mạnh hơn công tác 
tuyên truyền đa kênh để mỗi cá nhân đều nâng cao nhận thức bảo vệ môi trường. Nếu mức độ quen thuộc với các nhận thức hành vi bảo vệ môi trường càng cao thì sau đó họ sẽ có có nhiều ý định lựa chọn sản phẩm/ phương tiện xanh hơn (Wang \& Hazen, 2016).

Thứ tư, đối với nhân tố Nhận Thức kiểm soát hành vi $(\beta=0.170)$ có tác động thứ tư đến ý định mua xe máy điện của người dân trên địa bàn TP.HCM. Trong đó kết quả nghiên cứu cho thấy rằng hai biến quan sát có giá trị mean cao nhất Mean = 3.50 là KSHV2 "Mua hay không mua xe máy điện Vinfast là do tôi quyết định" và KSHV4 "Tôi nghĩ xe máy điện Vinfast dễ sử dụng", thấp nhất là biến quan sát KSHV3 "Tài chính của tôi có thể sở hữu được xe máy điện Vinfast" có giá trị Mean $=3.42$. Kết quả nghiên cứu đã cho thấy rằng người tiêu dùng ngày nay đều hầu hết kiểm soát hành vi của mình, chọn lọc thông tin kỹ càng và xem xét nguồn tài chính mà họ có trước khi ra quyết định mua hay không nên việc kế thừa yếu tố Nhận thức kiểm soát hành vi từ mô hình TPB là hoàn toàn phù hợp. Vì thế tác giả đề xuất rằng nhà quản lý nên chú trọng yếu tố "sự trải nghiệm", khách hàng không chỉ mỗi được trải nghiệm sản phẩm trực tiếp khi có nhu cầu mà còn có thể là sự trải nghiệm dịch vụ tư vẩn chuyên nghiệp, sự trải nghiệm về đẳng cấp thương hiệu mang lại để khách hàng thấy được những lợi ích và trải nghiệm tuyệt vời khi được sở hữu xe điện Vinfast. Ngoài ra, tác giả đề xuất doanh nghiệp Vinfast nên có chiến lược giá đa phân khúc để khách hàng có nhiều cơ hội hơn để sở hữu xe điện VF và được trải nghiệm các dịch vụ đi kèm.

Thứ năm, theo sau nhân tố Nhận thức kiểm soát hành vi là nhân tố Chuẩn chủ quan có $(\beta=0.169)$. Trong đó kết quả nghiên cứu cho thấy rằng biến quan sát $\mathrm{CQ} 4$ "Tôi chọn xe máy điện Vinfast vì người nổi tiếng mà tôi yêu thích là gương mặt đại diện cho xe điện Vinfast khuyên tôi nên sử dụng" có giá trị Mean $=3.50$ cao nhất và thấp nhất là biến quan sát CQ2 "Tôi quan tâm xe máy điện Vinfast vì người thân, bạn bè, đồng nghiệp khuyên tôi nên sử dụng xe máy điện Vinfast" có giá trị Mean $=3.42$. Hầu như những người tham gia cuộc khảo sát đều cho rằng ý định mua xe máy điện VF là do họ tự quyết định nên việc thu thập nhiều thông tin từ người thân, gia đình, bạn bè, những người đã từng sử dụng là điều cần thiết trước khi có ý định mua. Các doanh nghiệp nên nâng cao giá trị xã hội cho người sử dụng và sự trải nghiệm tích cực của sản phẩm thì khách hàng mới có những lời khuyên tích cực cho những đối tượng có ý định mua, tham khảo thông tin. Ngoài ba nhóm đối tượng được (Chen \& Chao, 2010) nhắc đến trong đề tài nghiên cứu của mình, sự tham khảo ý kiến từ cộng đồng mạng xã hội, cụ thể là nghe lời khuyên từ người nổi tiếng CQ4 "Tôi chọn xe máy điện Vinfast vì người nổi tiếng mà tôi yêu thích là gương mặt đại diện cho xe điện Vinfast khuyên tôi nên sử dụng" có giá trị Mean = 3.50 cao nhất. Nhận thấy biển CQ4 là một chiến lược khá thành công vừa qua nhờ việc hợp tác với ca sĩ Sơn Tùng cho ra mắt xe điện phiên bản giới hạn "VinFast Milky Sky và Ludo Mint To Be" nhằm gửi thông điệp "sống xanh, sống chất" dành riêng cho thế hệ gen $\mathrm{Z}$, trong tương lai các nhà quản lý có thể tiếp tục duy trì chiến lược hợp tác với KOL này như mời ca sĩ Hà Anh Tuấn làm gương mặt đại diện tiếp theo, tài trợ liveshow cho ca sĩ Hà Anh Tuấn gây quỹ trồng cây xanh, đồng thời quảng bá mạnh mẽ xe điện Vinfast của mình.

Thứ sáu, đối với nhân tố Chính sách khuyến mãi $(\beta=0.168)$ có tác động yếu nhất đến ý định mua xe máy điện của người dân trên địa bàn TP.HCM. Trong đó kết quả nghiên cứu cho thấy rằng Biến CSKM1 "Tôi nghĩ nhà nước nên có nhiều chính sách miễn giảm thuế khi mua xe máy điện Vinfast", có giá trị Mean = 3.83 cao nhất và thấp nhất là hai biến CSKM3 "Tôi nghĩ Vinfast nên có các chính sách mua xe điện trả góp hợp lý", CSKM4 "Tôi nghĩ Vinfast nên chú trọng đển chính sách ưu đãi bảo hiểm khi mua xe máy điện" đều có giá trị Mean = 3.69. Qua đó tác giả muốn đưa ra đề xuất hàm ý như sau: Về đề xuất ngắn hạn, chính phủ đẩy mạnh các chính sách miễn giảm thuế cho cả nhà kinh doanh và người mua hàng để khách hàng có cơ hội sở hữu xe điện xanh (Liao \& cộng sự, 2016). Trong dài hạn để cải thiện được biến CSKM3 và CSKM4, được coi là tác động yếu nhất đến biến ý định mua Vinfast nên tạo ra nhiều chương trình khuyến mãi "độc đáo" hơn để có thể thu hút sự chú ý của khách hàng một cách tốt nhất

\section{HẠN CHẾ CỦA ĐỀ TÀI VÀ HƯớNG NGHIÊN CÚU TIẾP THEO}

\subsection{Hạn chế của đề tài}

Mặc dù đã hoàn thành được mục tiêu của đề tài nghiên cứu, tuy nhiên tác giả nhận định vẫn còn một số hạn chế như sau:

Thứ nhất, thời gian thực hiện nghiên cứu khá hạn chế khi phải thực hiện hết tất cả các bước nghiên cứu trong thời gian ba tháng dẫn đến quá trình lựa chọn mô hình nghiên cứu, xây dựng thang đo trở nên gấp rút, chưa có sự đầu tư nhiều khiến ảnh hưởng đến kết quả dữ liệu sau nghiên cứu. 
Thứ hai, trong quá trình thực hiện nghiên cứu tác giả vẫn còn bị giới hạn trong việc tiếp cận các chuyên gia đầu ngành về lĩnh vực phương tiện xanh. Đối với quá trình thu thập dữ liệu sơ cấp cũng gặp một số khó khăn nhất định khi một số nguồn dữ liệu chưa thật sự minh bạch, rõ ràng.

Thứ ba, các đề tài nghiên cứu tiếp theo về ý định mua xe điện Vinfast tại khu vực TP.HCM cần phải tiến hành khảo sát với số lượng mẫu lớn hơn để đo lường được mức độ đại diện cho tổng thể.

\subsection{Hướng nghiên cứu tiếp theo}

Ở hướng nghiên cứu tiếp theo nên thực hiện nghiên cứu với số lượng mẫu lớn hơn cũng như là mở rộng phạm vi nghiên cứu để có cái nhìn khái quát hơn cho đề tài này.

Nên tìm kiếm nhiều hơn các tài liệu mới nhất trong ba năm gần đây để tổng hợp nội dung, áp dụng thêm nhiều biến khác vào để xem độ khả thi của các biến tác động đến ý định mua xe máy điện Vinfast của người dân địa bàn TP.HCM.

\section{TÀI LIỆU THAM KHẢO}

Ajzen, I. (1991). The Theory of Planned Behavior. Organization Behaviour and Human Decision Processes, 179211.

Ajzen, I. (2002). Residual effects of past on later behavior: Habituation and reasoned action perspectives.

Personality and Social Psychology Review, 107-122.

Ajzen, I., Fishbein, M. (1975). theory of reasoned action. Journal for the Theory of Social Behaviour, 155-163.

Armstrong, G., Adam, S., Denize, S., \& Kotler P. (2014). Principles of marketing.

Chen, C. F. \& Chao, W. H. (2010). Habitual or Reasoned? Using the Theory of Planned Behavior, Technology Acceptance Model, and Habit to Examine Switching Intention Toward Public Transit. Transporation Research.

Chorus, C. G., Koetse, M. J., \& Hoen, A. (2013). . Consumer preferences for alternative fuel vehicles: Comparing a utility maximization and a regret minimization model. Energy Policy, 901-908.

Dung, Đ. T. (2012). Nghiên cứu các yếu tố ảnh hưởng đến ý định sử dụng hệ thống tàu điện ngầm METRO tại Thành phố Hồ Chí Minh.

Glerum, A., Stankovikj, L., \& Bierlaire, M. . (2014). Forecasting the demand for electric vehicles: Accounting for attitudes and perceptions. Transportation Science, 48(4), 483-499.

Hà, H. (2019, 09). Đại chiến thị truờng xe máy điện. Được truy lục từ Tạp chí tài chính online: https://tapchitaichinh.vn/tai-chinh-kinh-doanh/dai-chien-thi-truong-xe-may-dien-313214.html

Hackbarth, A., \& Madlener, R. (2013). Consumer preferences for alternative fuel vehicles: A discrete choice analysis. . Transportation Research Part D: Transport and Environment, 5-17.

Hair, F., Black, C., Babin, J., \& Anderson, E. (2009). Multivariate Data Analysis. Pearson; 7th edition (February 23, 2009).

Hess, S., Fowler, M., \& Adler, T. (2012). A joint model for vehicle type and fuel type choice: Evidence. . Transportation, 39(3), 593-625.

Hoen, A., \& Koetse, M. J. (2014). A choice experiment on alternative fuel vehicle preferences of private car owners in the Netherlands. Transportation Research Part A: Policy and Practice, 199-215.

Huang, X. \& Ge, J. (2019). Electric vehicle development in Beijing: An analysis of consumer. Cleaner Production, 361-372.

IQAir. (2020). Chất lương không khí tại Việt Nam. Được truy lục từ IQAir: https://www.iqair.com/vi/vietnam

Kotler, P. (2007). Marketing căn bản. NXB Lao động - Xã hội.

Liao, F., Molin, E., \& Wee, B. (2016). Consumer preferences for electric vehicles: a literature review. Transport Reviews, 252-275.

Lịch sư phát triển và tuoong lai của xe điện. (2020). Được truy lục từ Thế giới xe điện: http://thegioixedien.com.vn/lich-su-phat-trien-va-tuong-lai-cua-xe-dien-c34n829.html 
Lim, J. X., Radzol, M., Cheah, J-H., \& Wong, M. W. (2017). The Impact of Social Media Influencers on Purchase Intention and the Mediation Effect of Customer Attitude. Asian Journal of Business Research, Volume 7, Issue 2.

Lộc, N. P. (2020). 6 Lý do nên chọn mua xe máy điện thay vì xe máy xăng. Được truy lục từ Điện máy xanh: https://www.dienmayxanh.com/kinh-nghiem-hay/6-ly-do-nen-chon-mua-xe-may-dien-thay-vi-xe-may-xa1215701

Lu, L.C., Chang, W. P. \& Chang, H. H. (2014). Consumer Attitudes toward Blogger's Sponsored Recommendations and Purchase Intention: The Effect of Sponsorship Type, Product Type, and Brand Awareness. Computers in Human Behavior, 258-266.

Ma, Y., Ke, Rou-Yu., Han, R., \& Tang, Bao-Jun. (2017). The analysis of the battery electric vehicle's potentiality of environmental effect: A case study of Beijing from 2016 to 2020. Journal of Cleaner Production, 395-406.

Mai, B. (2021). Hãng xe VinFast lỗ đúng kế hoạch hơn 6.500 tỷ đồng nưa đầu năm 2020. Được truy lục từ Tuổi trẻ Online: https://tuoitre.vn/hang-xe-vinfast-lo-dung-ke-hoach-hon-6-500-ti-dong-nua-dau-nam-20202020090918165097.htm\#: :text=N\%E1\%BB\%ADa\%20\%C4\%91\%E1\%BA\%A7u\%20n\%C4\%83m\%2020 20\%2C\%20Vingroup,vi\%E1\%BB\%87n\%2C\%20gi\%C3\%A10\%20d\%E1\%BB\%A5c\%E2\%80\%A6.)

Ngà, L. (2021). Xe máy điện 'lên ngôi', doanh số xe chạy xăng giảm mạnh. Được truy lục từ Việt Nam Finance: https://vietnamfinance.vn/xe-may-dien-len-ngoi-doanh-so-xe-chay-xang-giam-manh20180504224252816.htm

Nghiên cứu định luợng. (2021, 2 3). Được truy lục từ Wikipedia tiếng Việt: https://vi.wikipedia.org/wiki/Nghiên_cứu_định_lượng

Nghiên cứu định tính. (2021). Được truy lục từ Wikipedia tiếng Việt: https://vi.wikipedia.org/wiki/Nghiên_cứu_định_tính

Ô nhiếm môi trường ở mức báo động . (2020). Được truy lục từ Báo Người Lao Động: https://nld.com.vn/thoi-su/onhiem-moi-truong-o-muc-bao-dong-20200524224950558.htm

Phạm Thị Thu Trang. (2018). Phân tích các yếu tố ảnh hưởng đến ý định mua xe máy điện của người dân trên địa bàn quận Ninh Kiều - Cần Thơ.

Potoglou, D., \& Kanaroglou, P. S. (264-274). . Household demand and willingness to pay for clean vehicles. Transportation Research Part D: Transport and Environment, 12(4), 2007.

So sánh xe đạp điện và xe máy điện. (2020, 04 19). Được truy lục từ Thế giới xe điện: https://thegioixedien.com.vn/so-sanh-xe-dap-dien-va-xe-may-dien-khac-nhau-nhu-thenao\#: :text=V\%E1\%BA\%ADy\%20n\%C3\%AAn\%20\%C4\%91\%E1\%BB\%83\%20ph\%C3\%A2n\%20bi\%E $1 \% \mathrm{BB} \% 87 \mathrm{t}, \mathrm{t} \% \mathrm{E} 1 \% \mathrm{BB} \% 91 \mathrm{c} \% 20 \mathrm{kh} \% \mathrm{C} 3 \% \mathrm{~B} 4 \mathrm{ng} \% 20 \mathrm{qu} \% \mathrm{C} 3 \% \mathrm{~A} 1 \% 2050 \mathrm{~km} \% 2 \mathrm{Fh}$.

Taylor, S., \& Todd, P. A. (1995). Understanding Information Technology Usage: A Test of Competing Models. Information Systems Research 6, 144-176.

Thành phố Hồ Chí Minh. (2021). Được truy lục từ Wikipedia tiếng Việt: https://vi.wikipedia.org/wiki/Th\%C3\%A0nh_ph\%E1\%BB\%91_H\%E1\%BB\%93_Ch\%C3\%AD_Minh

Thoa, H. T. (2017). Nghiên cứu những nhân tố tác động tới quan hệ giữa ý định và hành vi tiêu dùng xanh của người tiêu dùng Việt Nam. Luận án tiến sĩ.

Thøgersen, J. (1999). Spill-over processes in the development of a sustainable consumption pattern. J. Econ. Psychol., 53-81. .

Thuy, T. T., \& Hong, T. T. P. (2019). Attitude to and Usage Intention of High School Students Toward Electric Two-Wheeled Vehicles in Hanoi City. Economics and Business, 47-62. 
Thuyết hành động hợp lý - Wikipedia Tiếng Việt. (2020, 5 29). Được truy lục từ Wikipedia Tiếng Việt: https://vi.wikipedia.org/wiki/Thuy\%E1\%BA\%BFt_h\%C3\%A0nh_\%C4\%91\%E1\%BB\%99ng_h\%E1\%BB $\% \mathrm{~A} 3 \mathrm{p} \_1 \% \mathrm{C} 3 \% \mathrm{BD}$

Trà, T. T. (2019). Các nhân tố ảnh hưởng đến ý định mua xe Vinfast của khách hàng Thành phố Hồ Chí Minh. Luận văn thac sĩ.

Trung, C. (2018). Xe điện VinFast bluetooth kết nối chen vào thị truoòng 90.000 tỉ. Được truy lục từ Báo tuổi trẻ: https://tuoitre.vn/xe-dien-vinfast-bluetooth-ket-noi-chen-vao-thi-truong-90-000-ti20181113083924689.htm

Uu và nhuợc của xe máy điện. (2019). Được truy lục từ Autobikes.vn: https://autobikes.vn/uu-va-nhuoc-cua-xemay-dien-6922.html

Vinfast đã bán được 67.000 ô tô và xe máy điện. (2020, 01 17). Được truy lục từ Vingroup website: https://www.vingroup.net/tin-tuc-su-kien/bai-viet/2138/vinfast-da-ban-duoc-67000-o-to-xe-may-dien

Wang, Y. \& Hazen, B.T. (2016). Consumer product knowledge and intention to purchase remanufactured products. Int. J. Prod. Econ., 460-469.

Xe điện VinFast chen vào thị truờng. (2018). Được truy lục từ Báo tuổi trẻ: https://tuoitre.vn/xe-dien-vinfastbluetooth-ket-noi-chen-vao-thi-truong-90-000-ti-20181113083924689.htm

Xe máy điện. (2021). Được truy lục từ Wikipedia: https://vi.wikipedia.org/wiki/Xe_m\%C3\%A1y_\%C4\%91i\%E1\%BB\%87n

Yi-Chang Ch., \& Gwo-Hshiung T. (1999). The market for electric scooters is accepted in Taiwan experience through the stated priority analysis. Transport Studies, Pergamon, Part D 4,, 127-146.

Ngày nhận bài: 06/05/2021

Ngày chấp nhận đăng: 16/07/2021 